\title{
Desarrollo de un sistema de catalogación y gestión de fotografías: Photon
}

Developing a system for cataloguing and managing photographs: Photon

\author{
Manuel BLÁZQUEZ OCHANDO \\ Departamento de Biblioteconomía y Documentación,Facultad de Ciencias de la Documentación, Universidad Complutense de \\ Madrid, Calle Santísima Trinidad 37, CP. 28010, manuel.blazquez@pdi.ucm.es
}

\begin{abstract}
Resumen
El objetivo de la investigación es plantear un modelo de análisis exhaustivo de la fotografía, a partir de las normas de descripción vigentes. Con este modelo, se desarrolla un sistema para la catalogación y gestión de archivos fotográficos. Su diseño lo habilita para gestionar todo tipo de autoridades involucradas en la descripción de la imagen, integrando herramientas para la edición de tesauros y detalles. De esta forma con el programa Photon, se pueden extraer detalles a modo de imágenes secundarias dependientes de una fotografía original, mejorando con ello las posibilidades de reutilización y recuperación de los fondos fotográficos.
\end{abstract}

Palabras clave: Automatización. Archivos fotográficos. Gestión de contenidos. Catalogación. Documentación fotográfica.

\section{Introducción}

La iniciativa para desarrollar un programa de gestión de archivos fotográficos, parte de la necesidad de unificar los métodos de catalogación de fotografías e imágenes de la forma más exhaustiva posible. Para ello, conviene recordar que (Blázquez Ochando, 2010a)

el análisis documental de la fotografía es la descripción de toda evidencia informativa, contextual, cognitiva, técnica, valorativa, denotativa y connotativa tanto del objeto propiamente visible en la imagen y sus detalles así como del objetivo y finalidad de la misma, su empleo, utilización y testimonio de un hecho, en un lugar, en un momento y en un soporte fijados.

Por ese mismo motivo, se detecta la necesidad de que la catalogación fotográfica sea soportada en todas sus dimensiones por sistemas informáticos adecuados a las necesidades documentales (Fox, 2003):

La catalogación debe estar soportada por un software que facilite y agilice la introducción de datos, y que permita el uso y recuperación de toda la información entrada; permitiendo al mismo tiempo la adopción de pautas de catalogación estandarizadas. Debe ser amigable y fácil de usar, igual en la introducción de datos que en la consulta y recuperación de la información. Debe contar con ayudas

\begin{abstract}
The purpose of this article is to propose a model for the comprehensive analysis of photographis, working on the current descriptive standards. From this model, we develop a system for cataloguing and managing photo files. All types of authorities involved in the description of the image can be managed and the system includes editing tools for integrating thesauri, details and typologies. In particular, the Photon program can extract secondary dependent images from the details of an original picture, thereby improving the reuse and retrieval of photographs.
\end{abstract}

Keywords: Automation. Photographic archives. Content management. Cataloguing. Photographic documentation.

como: campos flexibles, con opción a obligatoriedad, repetitividad, validación, máscaras..., distintas pantallas de trabajo; listas de consulta y validación de datos; multiplicidad y flexibilidad en la edición de resultados por pantalla, impresora o en línea. Distintos niveles de acceso y protección: contraseñas según el tipo de usuario, protecciones a la entrada, modificación y eliminación de datos, protección a la consulta de determinados campos... Debe contemplar la consulta en línea y, por último, debe prever la migración de datos a otros programas, bases de datos o catálogos.

Existen multitud de programas profesionales de gestión y catalogación fotográfica, entre ellos destacan las aplicaciones comerciales como Adobe Lightroom, Adobe Bridge, Acdsee, Aperture, iView, otras de código abierto como Darktable y finalmente aquellas disponibles en línea como servicios web, Picasa o Flickr. En todos los casos, tales programas son capaces de gestionar grandes volúmenes de imágenes, permitir la modificación y lectura de metadatos, la catalogación mediante etiquetado, la edición y tratamiento fotográficos, pero no abordan con enfoque documental aspectos claves como toda la variedad de autoridades posibles, los métodos de descripción del contexto y contenido de los elementos visibles en la fotografía, que aunados comportan la resolución de puntos de acceso para una recuperación de información 
equilibrada con el eminente y bien resuelto enfoque técnico.

Otro ejemplo significativo de estas carencias, se encuentra en investigaciones especializadas en documentación fotográfica (Crisafulli Rodrigues 2011 , p. 34) en las que se observa que de entre 21 programas especializados en catalogación fotográfica, sólo 12 de ellos permitían cubrir las especificaciones generales de la descripción.

En otros casos, las bibliotecas con archivos fotográficos, tratan de adaptar programas diseñados específicamente para la gestión bibliográfica y no fotográfica, debido a la alta afinidad de los especialistas con el análisis documental en MARC21 y AACR2, normas en las que por otra parte queda reflejada la fotografía (Casanova Huerta, 2010, p. 10-11).

Se observa pues que las carencias de unos sistemas son las virtudes de los demás, sin que parezca que exista una herramienta que aúne las capacidades técnicas y de gestión distribuida en red con las de catalogación a nivel macro y micro-descriptivo. Esta es una de las preocupaciones a las que se enfrentó la fototeca digital de la Universidad de Salamanca (Gómez Díaz et al., 2007, p. 189-191), en la que se aborda la necesidad de crear una base de datos especializada en la catalogación de documentos fotográficos que tenga en cuenta la importación de registros, opciones de consulta y búsqueda a texto completo, exportación de referencias bibliográficas de cara a la creación de catálogos fotográficos, el control de las autoridades, aportando sucesivamente una ficha de campos ideales para la descripción. En otros casos, no se aborda la creación de un nuevo sistema y se parte de programas de bases de datos ya establecidos, como sucede en el Archivo Fotográfico de la Unidad de Tratamiento Archivístico y Documentación del CSIC, que en 1996 adquirió el programa de bases de datos Inmagic $\mathrm{Db} / T$ extWorks, con el que se articula una ficha bibliográfico-descriptiva de 31 campos, entre los que no figuran aspectos de caracterización fotográfica como la estructura forma, la especialidad fotográfica, metadatos EXIF, historia de la procedencia, ingreso, acceso o fotografías relacionadas (Ibáñez González, 2009).

En cuanto a la recuperación automatizada de los acerbos fotográficos, viene resultando una tarea compleja resolver, por el escaso interés de diseñar programas descriptivos en beneficio de programas orientados a la gestión masiva de imágenes. Esta reflexión previa, no es novedosa, pues ya fue señalada por Sánchez Vigil (2002) refiriéndose a lo imprescindible de la labor digitalizadora de las fotografías, la preser- vación de las mismas y el análisis de los documentos de cara a su difusión extensiva, objetivo primordial, en la mayoría de las instituciones con archivos fotográficos históricos.

Asentando la investigación sobre estas premisas, la metodología a seguir se concreta en los siguientes apartados: (1) estudiar el análisis documental según la normativa vigente; (2) proponer un método de análisis compatible más exhaustivo; (3) diseñar un programa para la gestión y tratamiento documental de los archivos fotográficos, aplicando las ventajas de los modelos de descripción analizados; y (4) pruebas de funcionamiento, mejoras y futuras líneas de investigación.

\section{El análisis documental de la fotografía}

La primera fase de la investigación conlleva el análisis crítico de las principales normas de descripción, que atañen de forma directa al tratamiento del documento fotográfico. Se ha tomado como punto de referencia las áreas y campos recomendados en cada caso para el material específicamente fotográfico o de imagen fija en las normas ISBD, MARC21, ISAD-G y EXIF. Tal comparación puede resumirse en la Tabla I, en la página siguiente.

En el caso de las normas ISBD (IFLA, 2008), tal y como especifican en el apartado de alcance, objetivo y uso, están concebidas para cubrir desde textos impresos a recursos electrónicos, pasando por imágenes en movimiento, grabaciones sonoras y finalmente imágenes fijas y fotografías. Este amplio espectro de posibilidades, hace que el tratamiento específico de la fotografía pueda verse limitado en parte a favor de una mayor versatilidad en la aplicación de tales normas en terceros materiales. No obstante, un análisis más detenido de los campos esenciales en la catalogación de la fotografía con ISBD muestra un resultado favorable, si se tiene en cuenta el mantenimiento de los campos tradicionales de descripción para los diferentes casos de título que puede adoptar la fotografía, la definición de la clase de documento, del autor de la fotografía y fundamentalmente la posibilidad de contemplar el soporte, material, información específica relativa a la reproducción o visualización de la fotografía, el color, la técnica fotográfica empleada, la emulsión y las dimensiones de la misma.

También resultan esenciales los campos de normalización que contienen números normalizados e identificadores, ya que cada vez con mayor frecuencia las fotografías son producidas desde los propios centros catalogadores, incorporando URL, entre otros. 


\begin{tabular}{|c|c|}
\hline$I S B D$ & MARC21 \\
\hline $\begin{array}{l}\text { Título y mención de } \\
\text { responsabilidad } \\
\text { Título } \\
\text { Clase de documento } \\
\text { Otras formas del título } \\
\text { Autor - responsabilidad } \\
\text { Edición } \\
\text { Publicación } \\
\text { Lugar } \\
\text { Editor } \\
\text { Fecha de publicación } \\
\text { Descripción física } \\
\text { Material } \\
\text { Soporte } \\
\text { Reproducción } \\
\text { Color } \\
\text { Técnica fotográfica } \\
\text { Emulsión } \\
\text { Dimensiones - formato } \\
\text { Serie } \\
\text { Título de serie } \\
\text { Número de la serie } \\
\text { Autor - responsabilidad } \\
\text { ISSN } \\
\text { Notas } \\
\text { Registro y normalización } \\
\text { Número normalizado } \\
\text { Título clave } \\
\text { ISBN } \\
\text { DOI } \\
\text { URI }\end{array}$ & $\begin{array}{l}\text { Control } \\
\text { Número de control } \\
\text { Código de referencia del centro } \\
\text { Fecha de modificación } \\
\text { Número y código } \\
\text { ISBN, ISSN, URI, DOI } \\
\text { Clasificación o ubicación } \\
\text { Localización topográfica } \\
\text { Categoría temática } \\
\text { Clasificación decimal } \\
\text { Entrada principal } \\
\text { Persona, Entidad, Reunión } \\
\text { Títulos } \\
\text { Título abreviado, clave, unifor- } \\
\text { me, paralelo, propiamente dicho } \\
\text { Edición y publicación } \\
\text { Mención de edición } \\
\text { Lugar de publicación } \\
\text { Editorial } \\
\text { Fecha de publicación } \\
\text { Descripción física } \\
\text { Extensión } \\
\text { Detalles físicos } \\
\text { Dimensiones } \\
\text { Material anejo } \\
\text { Mención de serie } \\
\text { Título de serie } \\
\text { Número de la serie o parte } \\
\text { Notas }\end{array}$ \\
\hline$I S A D-G$ & Metadatos EXIF \\
\hline $\begin{array}{l}\text { Identificación } \\
\text { Código de referencia } \\
\text { Título general } \\
\text { Fecha de creación } \\
\text { Nivel de descripción } \\
\text { Volumen de la unidad } \\
\text { Contexto } \\
\text { Nombre del productor } \\
\text { Fecha de toma de la foto } \\
\text { Historia de la custodia } \\
\text { Forma de ingreso } \\
\text { Contenido y estructura } \\
\text { Resumen } \\
\text { Valoración, selección, eliminación } \\
\text { Nuevos ingresos } \\
\text { Organización de la documentación } \\
\text { Área de condiciones de acceso } \\
\text { y uso } \\
\text { Situación jurídica } \\
\text { Condiciones de acceso } \\
\text { Derechos de autor } \\
\text { Lengua del documento } \\
\text { Instrumento de descripción } \\
\text { Documentación asociada } \\
\text { Localización } \\
\text { Existencia de copias } \\
\text { Unidades relacionadas } \\
\text { Bibliografía } \\
\text { Notas } \\
\text { Información complementaria }\end{array}$ & $\begin{array}{l}\text { Técnica } \\
\text { ExifVersion } \\
\text { UserComment } \\
\text { ExposureTime } \\
\text { FNumber } \\
\text { ISOSpeedRatings } \\
\text { ShutterSpeedValue } \\
\text { ApertureValue } \\
\text { BrightnessValue } \\
\text { SpectralSensitivity } \\
\text { FocalLength } \\
\text { DateTime } \\
\text { MimeType } \\
\text { Make } \\
\text { Model } \\
\text { XResolution } \\
\text { YResolution } \\
\text { IsColor } \\
\text { Metadatos Dublin Core } \\
\text { Metatos } \\
\text { Contenido } \\
\text { Título } \\
\text { Materia } \\
\text { Descripción } \\
\text { Fuente } \\
\text { Relación } \\
\text { Cobertura } \\
\text { Propiedad intelectual } \\
\text { Autor } \\
\text { Editor } \\
\text { Colaborador } \\
\text { Derechos } \\
\text { Aplicación } \\
\text { Fecha } \\
\text { Formato } \\
\text { Identificador } \\
\text { Tipo de objeto } \\
\text { Idioma }\end{array}$ \\
\hline
\end{tabular}

Tabla I. Análisis documental, archivístico y técnico según las normas

Si bien la libertad del área de descripción física en ISBD ha de considerarse beneficiosa, pasa por alto los inevitables aspectos técnicos de la fotografía, que pueden resultar difíciles de sistematizar en unas normas diseñadas para su adopción general y posterior especialización y adaptación a las necesidades de cada centro o unidad de información y documentación.
En relación a las normas MARC21 de la Library of Congress, constituyen un punto de referencia ineludible, si se tiene en cuenta el importante crecimiento y tradición del fondo fotográfico de la institución (LOC, 2010). Su ámbito de aplicación resulta similar al pretendido por las normas ISBD pero con la diferencia esencial de que MARC21 fue diseñado para un uso informatizado que se aproxima más al registro bibliográfico contenido en base de datos. El empleo de códigos identificativos para las áreas, campos, así como de calificadores que determinan la casuística de la descripción, permiten efectuar precisiones de interés para el especialista en documentación fotográfica. Ello se concreta en la localización topográfica de la imagen, la definición del medio, la fecha de publicación, la descripción física y un aspecto no contemplado hasta el momento, la colección de la que forma parte, reconocido este punto como un apartado concreto del estándar.

En relación a las normas de descripción archivística ISAD-G (ICA, 2010), conviene recordar que su ámbito de aplicación es el archivo en sentido general, incluyendo la identificación, contexto y contenido de las agrupaciones documentales como el fondo, sección, serie y expediente a lo largo del ciclo vital de la institución sujeta al análisis, como resultado de su relación con otras instituciones, personas físicas, jurídicas y en el desempeño de sus funciones. Teniendo en cuenta estos aspectos, resulta habitual encontrar en los expedientes, documentación fotográfica, que en muchos casos sirve de respaldo en los procedimientos administrativos, así como con la propia digitalización de los documentos que da como resultado un archivo digital, paralelo al archivo físico.

Aún no pudiéndose comparar un documento digitalizado con una fotografía aérea para la delimitación de lindes, en ambos casos se suceden una serie necesidades de descripción sobre la imagen que ponen a prueba la flexibilidad del estándar de descripción archivística. Un ejemplo de esta adaptación se encuentra en la UTAD del CSIC (Chica Blanco et al., 2009, p. 31 ), en la que, para determinar el modelo de descripción de los fondos fotográficos, se recurre a la fusión de los campos útiles de la propia ISAD-G, las reglas angloamericanas AACR2R o el proyecto SEPIA (Digital Curation Centre, 2012).

La potencial capacidad de adaptación de la descripción archivística al caso de la fotografía, se comprueba especialmente en los campos de contexto, contenido, acceso y documentos asociados, desde los que es posible definir al autor de la fotografía, la historia de la custodia de la 
misma, la fecha de toma de la foto, su contexto histórico, valoración o reenvío a terceros materiales relacionados. Añadidas a estas posibilidades, cabe destacar el vínculo con las normas ISAAR-CPF (ICA, 2004), especializadas en la descripción de autoridades, personas, familias y entidades; y, por otro lado, la norma ISAF (ICA, 2007), especializada en la descripción funcional de las autoridades. Todo ello conforma un corpus descriptivo en el que la fotografía podría ser descrita no sólo en virtud de sus contenidos y valores implícitos, sino también por la relación de las personas e instituciones involucradas en su historia. En este punto, la documentación fotográfica y la archivística encuentran un nexo de unión que no debe ser separado, si se desea obtener un cuadro de análisis lo más exhaustivo y preciso posible.

Para abordar los aspectos técnicos de la fotografía, otro componente del continente fotográfico, son los metadatos EXIF (TSC-AV; IT-SSE, 2002), portados en los formatos de fotografía digital. Sorprendentemente si bien permiten una descripción completa del apartado técnico, tal y como se preveía, no se obtiene el mismo resultado en cuanto a su capacidad de descripción documental, por motivos obvios. Obsérvese que, en la Tabla I, los metadatos EXIF hacen referencia a propiedades físicas, cromáticas, lumínicas, ópticas, de resolución o dimensiones, pero no a las propiedades contextuales de la imagen. Podría aducirse que los metadatos EXIF, junto con los metadatos Dublin Core (Hillmann, 2005) constituyen un método de descripción perfectamente válido; y en efecto lo es, por ser breve, sencillo y muy claro. Pero cuando la fotografía toma una caracterización distinta de la generalidad, este modelo deja de ser efectivo.

Un ejemplo de caracterización especializada de la imagen es aquella de corte foto-periodístico. Es muy posible que los elementos de descripción previstos por Dublin Core y EXIF sean insuficientes y muchos detalles no queden recogidos, pues la imagen forma parte indisoluble de una noticia y requiere descripción, pie de foto, contextos, estados de la publicación, párrafos destacados, titulares y fotografías relacionadas, entre otros. Para tal caso, también existe una norma de descripción denominada NewsML G2 desarrollada por el International Press Telecommunications Council (IPTC, 2011).

En otro orden del análisis se deben conocer los enfoques de los especialistas en documentación fotográfica. Así, Argerich (1997, p. 71-113) considera esencial la descripción de los procesos físico-químicos que determinan la composición de la fotografía en su soporte (calotipo, platinotipo, albúmina, colodión, daguerrotipo), defi- niendo como campos esenciales la técnica del proceso fotográfico (monocromo, negativo, positivo), la identificación de la emulsión (haluros de plata fotonsensibles, bromuros, yoduros) y el tipo de revelado. La perspectiva técnica definida por la autora resulta clave para la descripción de fotografías históricas; y, por ello, el diseño de un programa de catalogación de acerbos fotográficos debería contemplar la posibilidad de definir claramente todas las posibilidades materiales.

Según Valle Gastaminza (1999, p. 113-131) el análisis de la fotografía parte de la identificación de un referente claro, sus elementos interpretantes como el pie de foto y la propia iconicidad de la fotografía. Otra propiedad destacada es la polisemia o interpretación de la imagen que varía dependiendo de la época y valores que la fotografía adquiere, sobre todo aplicado al caso de la fotografía histórica. También se señala cómo la elección de las propiedades físicas y técnicas, como el uso de un determinado tipo de emulsión, el uso de objetivos de visión distorsionada, el tiempo de exposición de la imagen, el tipo de cámara utilizada, el encuadre o la captación de un instante espontáneo, pueden ser determinantes para su tratamiento documental y su reutilización. Teniendo en cuenta tales aspectos, el autor observa como campos fundamentales aquéllos relativos a la identificación de los elementos fotografiados, esto es, la definición de autoridades personales, lugares, objetos, acciones y situaciones, así como la distinción de los elementos connotativos y denotativos de la imagen, bien empleando descriptores geográficos, onomásticos, cronológicos o temáticos. También señala la importancia del contexto de la imagen (histórico, político, social, cultural) y su descripción, como los materiales que acompañan a la fotografía.

Sánchez Vigil (1999, p. 144-155) precisa de forma acertada que los condicionantes del proceso de análisis documental, no solamente vienen dados por el documento fotográfico en sí, sino por las características competenciales del documentalista y los complementos textuales de la imagen que se viene a describir y comprender. Tomando esta observación como antecedente se articulan tres ejes del análisis de la fotografía, la identificación propiamente dicha, la morfología de la imagen y el estudio de los contenidos y su significado. También aporta una visión de ciclo vital del documento fotográfico al considerar la génesis de la fotografía, la incoación, el tratamiento descriptivo, la aplicación o uso principal de la imagen y finalmente la conservación y difusión de la fotografía como objeto artístico, histórico o fedatario. Por ello, no es difícil encontrar en su obra referencias comple- 
tas a las normas ISAD-G, que también recomienda para la unificación y tratamiento de la documentación.

Esta visión es ampliada (Sánchez Vigil, 2006, p. 169-222) aportando una serie de campos descriptivos considerados claves para la reutilización de la imagen y que a priori no deberían de faltar en ningún programa de gestión de archivos fotográficos, estos son; el formato, el soporte, autor fotógrafo, agencia, resumen descriptivo de lo retratado, descriptores, número de registro del sistema, número de registro original, signatura topográfica, orden de procedencia, usos y aplicaciones de la fotografía y derechos.

Se puede resumir que, dependiendo de la caracterización y tipología de los fondos fotográficos, las necesidades descriptivas se perfilan diferentes. Por ese motivo, resulta complejo el desarrollo de un programa informático para atender a todas estas perspectivas (análisis documental de la fotografía, artística, histórica, jurídico-legal, administrativa, periodísticoinformativa, científico-tecnológica).

\section{Propuesta de análisis}

Como resultado del estudio comparativo de las diferentes normas, estándares y recomendaciones de especialistas en documentación fotográfica, se concibió un esquema de catalogación único que tuviera en cuenta todos los aspectos beneficiosos para la descripción, asegurando a la vez su compatibilidad con ISBD, MARC21, ISAD-G, ISAAR-CPF, ISAF, EXIF y Dublin Core. (Tabla II).

\begin{tabular}{ll}
\hline Campos de control \\
\hline Identificador & $\begin{array}{l}\text { Toda fotografía debe ser registrada con } \\
\text { algún tipo de número de registro, } \\
\text { correlativo, normalizado, propio del centro } \\
\text { catalogador, o externo como DOI, URI, etc. }\end{array}$ \\
\hline Tipo de material & $\begin{array}{l}\text { Digital, reproducción digital de un positivo, } \\
\text { reproducción digital de un negativo, } \\
\text { positivo, negativo, contactos. }\end{array}$ \\
\hline $\begin{array}{l}\text { URL de imagen en } \\
\text { alta resolución }\end{array}$ & $\begin{array}{l}\text { La dirección o ruta en la que se almacena el } \\
\text { archivo de la fotografía de alta resolución. }\end{array}$ \\
\hline $\begin{array}{l}\text { URL de imagen en } \\
\text { baja resolución }\end{array}$ & $\begin{array}{l}\text { La dirección o ruta en la que se almacena el } \\
\text { archivo de la fotografia de baja resolución o } \\
\text { thumbnail. }\end{array}$ \\
\hline $\begin{array}{l}\text { Localización } \\
\text { topográfica }\end{array}$ & $\begin{array}{l}\text { La localización topográfica que identifica la } \\
\text { posición, estantería u orden que ocupa la } \\
\text { fotografía en la fototeca o centro de } \\
\text { documentación. }\end{array}$ \\
\hline Identificación \\
\hline Parte de colección & $\begin{array}{l}\text { Identificación de la colección de la que } \\
\text { forma parte la fotografía. }\end{array}$ \\
\hline
\end{tabular}

\begin{tabular}{|c|c|c|}
\hline Título & \multicolumn{2}{|c|}{$\begin{array}{l}\text { Titulo propiamente dicho de la fotografía, en caso } \\
\text { de que fuera aportado por el autor. }\end{array}$} \\
\hline $\begin{array}{l}\text { Subtítulo o } \\
\text { título alternativo }\end{array}$ & \multicolumn{2}{|c|}{$\begin{array}{l}\text { Título alternativo, subtítulo o título atribuido de la } \\
\text { imagen. }\end{array}$} \\
\hline Descripción & \multicolumn{2}{|c|}{$\begin{array}{l}\text { La descripción de la fotografía responderá a una } \\
\text { narración completa sobre qué personas aparecen } \\
\text { en la fotografia, qué escena se ve representada } \\
\text { (personajes históricos, investigadores, políticos, } \\
\text { personajes de sociedad, etc.), qué objetos } \\
\text { aparecen (objetos de arte, edificios, objetos } \\
\text { urbanos, objetos de escritorio, mobiliario, joyas y } \\
\text { abalorios, automoción, máquinas, etc.), qué } \\
\text { acciones pueden apreciarse (pose, firma de un } \\
\text { documento, lectura, diálogo, etc.), en qué planos } \\
\text { en los que se encuentran los objetos y personas } \\
\text { retratadas, en qué lugar se tomo la fotografia, en } \\
\text { qué fecha. }\end{array}$} \\
\hline \multirow[t]{6}{*}{ Caracterización } & Plano & $\begin{array}{l}\text { Describir el plano principal } \\
\text { dominante en la imagen (plano } \\
\text { picado, contrapicado, cenital, } \\
\text { nadir, primer plano, etc.) }\end{array}$ \\
\hline & Encuadre & $\begin{array}{l}\text { Tipo de encuadre de la } \\
\text { fotografía (horizontal, vertical, } \\
\text { panorámico, etc.) }\end{array}$ \\
\hline & $\begin{array}{l}\text { Estructura } \\
\text { formal }\end{array}$ & $\begin{array}{l}\text { Determinar si la fotografía es } \\
\text { un retrato, una escena, un } \\
\text { paisaje, un bodegón, collage, } \\
\text { etc. }\end{array}$ \\
\hline & $\begin{array}{l}\text { Especialidad } \\
\text { fotográfica }\end{array}$ & $\begin{array}{l}\text { Intrínseca al valor de la } \\
\text { fotografía. Fotografía artística, } \\
\text { informativa, documental, } \\
\text { publicitaria, etc. }\end{array}$ \\
\hline & Formato & $\begin{array}{l}\text { Tamaño estándar o tradicional } \\
\text { predeterminado en la fotografía } \\
\text { o dimensiones. }\end{array}$ \\
\hline & $\begin{array}{l}\text { Soporte } \\
\text { original }\end{array}$ & $\begin{array}{l}\text { Soporte de la fotografía } \\
\text { (daguerrotipo - metal, } \\
\text { albúmina - vidrio, poliéster - } \\
\text { plástico, etc.) }\end{array}$ \\
\hline \multirow[t]{5}{*}{ Contextos } & Histórico & $\begin{array}{l}\text { Definición del contexto } \\
\text { histórico en relación a la fecha } \\
\text { en la que se tomó la fotografía, } \\
\text { así como las connotaciones } \\
\text { que ésta pudiera tener para } \\
\text { explicar un suceso histórico. }\end{array}$ \\
\hline & $\begin{array}{l}\text { Situación o } \\
\text { estado }\end{array}$ & $\begin{array}{l}\text { Descripción del contexto } \\
\text { general que envuelve la } \\
\text { escena representada en la } \\
\text { fotografía. (Por ejemplo, una } \\
\text { reunión, una comparecencia, } \\
\text { una acción policial, una } \\
\text { manifestación, etc.) }\end{array}$ \\
\hline & $\begin{array}{l}\text { Social y } \\
\text { cultural }\end{array}$ & $\begin{array}{l}\text { Descripción del contexto social } \\
\text { y cultural que envuelve a la } \\
\text { fotografía. (Por ejemplo, una } \\
\text { reunión de intelectuales de la } \\
\text { generación del } 14 \text {, la lectura de } \\
\text { un tratado científico o una } \\
\text { tesis.) }\end{array}$ \\
\hline & Espacial & $\begin{array}{l}\text { Descripción del contexto } \\
\text { espacial, en aquellos casos en } \\
\text { los que se puedan dar más } \\
\text { detalles que una simple } \\
\text { localización. (Por ejemplo, la } \\
\text { calle principal y los edificios } \\
\text { colindantes representados en } \\
\text { la fotografía.) }\end{array}$ \\
\hline & Temporal & $\begin{array}{l}\text { Descripción exhaustiva del } \\
\text { periodo o fecha en la que se } \\
\text { tomó la fotografía. En caso de } \\
\text { aproximaciones en la datación }\end{array}$ \\
\hline
\end{tabular}




\begin{tabular}{|c|c|c|}
\hline & & se explicará cuál y porqué. \\
\hline \multirow[t]{3}{*}{ Derechos } & $\begin{array}{l}\text { Tipo de } \\
\text { derechos }\end{array}$ & $\begin{array}{l}\text { Bajo qué tipo de derechos se } \\
\text { acoge la fotografía (GPL, } \\
\text { Copyleft, Copyright, Creative } \\
\text { Commons) }\end{array}$ \\
\hline & $\begin{array}{l}\text { Derechos de } \\
\text { explotación }\end{array}$ & $\begin{array}{l}\text { Cuál es la casuística de los } \\
\text { derechos morales y de } \\
\text { explotación que afectan a la } \\
\text { imagen. (Por ejemplo, el uso } \\
\text { comercial, divulgación, } \\
\text { reproducción, difusión limitada, } \\
\text { permisos para editar obras } \\
\text { derivadas, etc.) }\end{array}$ \\
\hline & $\begin{array}{l}\text { Cláusulas } \\
\text { especiales }\end{array}$ & $\begin{array}{l}\text { Qué otras cláusulas o } \\
\text { conceptos han de tenerse en } \\
\text { cuenta al tratar o editar la } \\
\text { fotografía, no convenidos } \\
\text { originalmente en el tipo de } \\
\text { licencia. (Por ejemplo, precio } \\
\text { por uso, casos de explotación } \\
\text { aprobada por el autor, etc.) }\end{array}$ \\
\hline
\end{tabular}

Datos técnicos

\begin{tabular}{|c|c|}
\hline Tipo MIME & $\begin{array}{l}\text { Definición de extensiones multipropósito de } \\
\text { correo de internet para imágenes. (Por ejemplo, } \\
\text { jpeg, png, gif, tiff, svg, etc.) }\end{array}$ \\
\hline Tamaño & $\begin{array}{l}\text { Dimensiones exactas de la fotografía en } \\
\text { centímetros y píxeles. }\end{array}$ \\
\hline Resolución & $\begin{array}{l}\text { Resolución expresada en píxeles por pulgada } \\
\text { (Por ejemplo, 300ppi). }\end{array}$ \\
\hline Color & $\begin{array}{l}\text { Descripción del color en la fotografía, RGB, } \\
\text { Grises, Sepia o Negativo. También podrá } \\
\text { especificarse el predominio de un color en } \\
\text { especial. }\end{array}$ \\
\hline Cámara & Marca de la cámara de fotos. \\
\hline Modelo & $\begin{array}{l}\text { Nombre completo del modelo de cámara de } \\
\text { fotos. }\end{array}$ \\
\hline Objetivo & $\begin{array}{l}\text { Definición del objetivo o lente empleado en la } \\
\text { fotografía. }\end{array}$ \\
\hline $\begin{array}{l}\text { Tiempo de } \\
\text { exposición }\end{array}$ & $\begin{array}{l}\text { Tiempo de exposición que se mantiene abierto el } \\
\text { obturador de la cámara hasta que se toma la } \\
\text { fotografía. }\end{array}$ \\
\hline $\begin{array}{l}\text { Número de F- } \\
\text { stop }\end{array}$ & $\begin{array}{l}\text { Definición de extensiones multipropósito de } \\
\text { correo de internet para imágenes. }\end{array}$ \\
\hline Distancia focal & $\begin{array}{l}\text { Es la distancia entre la lente y el foco o punto } \\
\text { focal a partir del cual se enfoca la imagen. }\end{array}$ \\
\hline Velocidad ISO & $\begin{array}{l}\text { Es la escala de sensibilidad fotográfica de una } \\
\text { película o sensor digital a la luz durante la toma } \\
\text { de la fotografía. }\end{array}$ \\
\hline Luz & $\begin{array}{l}\text { Tipo de luz que afecta a la fotografía en la } \\
\text { fotografía. }\end{array}$ \\
\hline \multicolumn{2}{|r|}{ Fechas } \\
\hline $\begin{array}{l}\text { Fecha de toma } \\
\text { de la foto }\end{array}$ & $\begin{array}{l}\text { Fecha exacta o aproximada en la que se tomó la } \\
\text { fotografía, datación. }\end{array}$ \\
\hline $\begin{array}{l}\text { Fecha de } \\
\text { catalogación }\end{array}$ & $\begin{array}{l}\text { Fecha exacta en la que se cataloga o actualiza la } \\
\text { catalogación de la fotografía. }\end{array}$ \\
\hline \multicolumn{2}{|r|}{ Sujeto productor } \\
\hline Autor personal & $\begin{array}{l}\text { Autoridad personal, autora de la fotografía. El } \\
\text { fotógrafo forma parte del registro de autoridades } \\
\text { y requiere de una descripción completa que } \\
\text { comprende la ocupación, fechas extremas, } \\
\text { descripción biográfica, datos de contacto, } \\
\text { laboratorio de producción y fotografía. }\end{array}$ \\
\hline
\end{tabular}

\begin{tabular}{ll}
\hline Autor familia & $\begin{array}{l}\text { La familia se considera una autoridad } \\
\text { propiamente dicha. En el caso de que deba } \\
\text { considerarse su mención de responsabilidad o } \\
\text { autoría conjunta en la descripción de la } \\
\text { fotografía, deberá describirse además su } \\
\text { denominación completa, miembros de la familia, } \\
\text { fechas extremas, descripción biográfica y datos } \\
\text { de contacto. }\end{array}$ \\
\hline Autor & $\begin{array}{l}\text { También considerado como autor-corporativo o } \\
\text { corporativo }\end{array}$ \\
& $\begin{array}{l}\text { editoriales, medios de comunicación y agencias } \\
\text { de fotografía adquieren los derechos de la } \\
\text { fotografía y, por lo tanto, la autoridad para } \\
\text { explotar la información gráfica de las mismas. En } \\
\text { este caso se deberá describir además la } \\
\text { ocupación de la entidad, denominación completa, } \\
\text { fechas extremas, descripción historiográfica y } \\
\text { datos de contacto. }\end{array}$ \\
\hline Productor & $\begin{array}{l}\text { En el caso de que el sujeto productor sea un } \\
\text { coleccionista u ostente una colección de } \\
\text { fotografías propias, podrá identificarse su } \\
\text { denominación completa, ocupación, fechas } \\
\text { extremas, descripción biográfica, datos de } \\
\text { contacto y relación con el nombre de la } \\
\text { colección/es correspondientes. }\end{array}$ \\
\hline
\end{tabular}

\section{Autoridades}

Personal Se registrarán todas las autoridades personales conocidas de la fotografía, describiendo ocupación o dedicación, descripción biográfica, datos de contacto, tipo de autoridad personal y fechas extremas.

Corporativa Se registrarán todas las entidades o personas jurídicas que pudieran ser identificadas en la fotografía, describiendo de igual modo a qué tipo de entidad corresponde, ocupación, descripción, fechas extremas, etc.

Familia Cuando el objeto de la fotografía es un retrato de familia o parte de ella, ésta deberá constar como autoridad reconocida, describiendo de igual modo los campos comunes a las autoridades onomásticas.

Encuentros o Cualquier encuentro, acto o evento que esté eventos representado en la fotografía, debe ser identificado y forma parte de las listas de autoridades de la fototeca. Deberá determinarse qué jornadas, seminarios, congresos, reuniones, consejos, aniversarios... corresponden para que forme parte de los puntos de acceso de la fotografía.

Editoriales Las autoridades editoriales deberán describirse en el caso de que la entidad como tal aparezca en la fotografía, o reproduzca una fotografía dada, o su participación en la acción o escena sea probada. Se prescriben los mismos aspectos de descripción que en las autoridades anteriores.

Localización o Se consignarán las localizaciones o lugares que lugar fueren necesarios para determinar la ubicación exacta de la fotografía, constituyendo por ende una autoridad geográfica. Se describirá el tipo de autoridad geográfica (ciudad, región, edificio, plaza), su denominación completa ([dirección completa] ; [código postal],[ciudad] ;

[lugar],[región] ; [país]), fechas extremas, descripción historiográfica o aclaratoria y URI de geo-posicionamiento.

\begin{tabular}{lll}
\hline & \multicolumn{2}{c}{ ISAD-G } \\
\hline $\begin{array}{l}\text { Formas de } \\
\text { ingreso y } \\
\text { adquisición }\end{array}$ & $\begin{array}{l}\text { Tipo de } \\
\text { ingreso }\end{array}$ & $\begin{array}{l}\text { Se determina si la fotografía } \\
\text { fue adquirida por medio de } \\
\text { compra, permuta, donación, } \\
\text { intercambio o préstamo. }\end{array}$ \\
\cline { 2 - 3 } & Descripción & $\begin{array}{l}\text { Se describe la modalidad de } \\
\text { ingresos, bajo qué }\end{array}$ \\
\hline
\end{tabular}




\begin{tabular}{|c|c|c|}
\hline & & $\begin{array}{l}\text { condiciones, la historia propia } \\
\text { de la adquisición. }\end{array}$ \\
\hline & Procedencia & $\begin{array}{l}\text { Cuál es la persona física o } \\
\text { jurídica, así como institución } \\
\text { que ha transmitido la fotografía } \\
\text { al centro catalogador. }\end{array}$ \\
\hline & Fechas & $\begin{array}{l}\text { Se determinan las fechas de } \\
\text { ingreso y de entrega de la } \\
\text { fotografía si procede. }\end{array}$ \\
\hline \multirow[t]{2}{*}{ Valoración } & $\begin{array}{l}\text { Estado de } \\
\text { conservación }\end{array}$ & $\begin{array}{l}\text { Se determina el estado de } \\
\text { conservación de la fotografía } \\
\text { como bueno, malo o regular en } \\
\text { función a las taras que ésta } \\
\text { presente. }\end{array}$ \\
\hline & $\begin{array}{l}\text { Valores del } \\
\text { documento }\end{array}$ & $\begin{array}{l}\text { Descripción de los valores } \\
\text { testimoniales de fe pública, } \\
\text { valor probatorio, valor } \\
\text { administrativo y legal, valor } \\
\text { histórico. }\end{array}$ \\
\hline \multirow[t]{2}{*}{$\begin{array}{l}\text { Condiciones de } \\
\text { acceso y uso }\end{array}$} & $\begin{array}{l}\text { Tipo de } \\
\text { acceso }\end{array}$ & $\begin{array}{l}\text { Se definirá el tipo de acceso } \\
\text { libre, limitado o restringido en } \\
\text { función del estado de } \\
\text { conservación de la fotografía. }\end{array}$ \\
\hline & Descripción & $\begin{array}{l}\text { Se describen las condiciones } \\
\text { de acceso a la fotografía, así } \\
\text { como las formas de } \\
\text { reproducción de la misma. }\end{array}$ \\
\hline $\begin{array}{l}\text { Documentación } \\
\text { asociada }\end{array}$ & \multicolumn{2}{|c|}{$\begin{array}{l}\text { Existencia y localización de documentos } \\
\text { originales, copias y unidades documentales } \\
\text { relacionadas. }\end{array}$} \\
\hline \multirow[t]{2}{*}{ Notas } & General & $\begin{array}{l}\text { Se describen aspectos } \\
\text { generales que no hayan } \\
\text { podido ser consignados en los } \\
\text { campos anteriores. }\end{array}$ \\
\hline & Bibliografía & $\begin{array}{l}\text { Se anotarán todas las } \\
\text { referencias bibliográficas que } \\
\text { permitan estudiar la fotografía } \\
\text { o cualquiera de los aspectos } \\
\text { que ésta refleje. }\end{array}$ \\
\hline \multicolumn{3}{|c|}{ Detalles } \\
\hline $\begin{array}{l}\text { Detalles asignados } \\
\text { Coordenadas } \\
\text { Título del detalle } \\
\text { Tipología de detalles } \\
\text { Fechas extremas } \\
\text { Descripción } \\
\text { Palabras clave }\end{array}$ & & $\begin{array}{l}\text { Se relacionarán todos los } \\
\text { detalles de la fotografía } \\
\text { catalogándolos de forma } \\
\text { independiente de tal forma que } \\
\text { la fotografía principal pueda } \\
\text { ser recuperada por ellos si esto } \\
\text { fuera preciso. }\end{array}$ \\
\hline \multicolumn{3}{|c|}{ Clasificación } \\
\hline $\begin{array}{l}\text { Tesauro } \\
\text { Término general } \\
\text { Término específico } 1 \\
\text { Término específico } 2\end{array}$ & & $\begin{array}{l}\text { La fotografía se clasificará } \\
\text { mediante categorías temáticas } \\
\text { normalizadas, definidas en un } \\
\text { tesauro al uso. }\end{array}$ \\
\hline Palabras clave & \multicolumn{2}{|c|}{$\begin{array}{l}\text { Se utilizarán las } 5 \text { palabras clave que definan la } \\
\text { fotografía, formando parte de una ontología y del } \\
\text { sistema de etiquetado del programa. }\end{array}$} \\
\hline $\begin{array}{l}\text { No palabras } \\
\text { clave }\end{array}$ & \multicolumn{2}{|c|}{$\begin{array}{l}\text { Se utilizarán las } 5 \text { palabras antónimas a las clave } \\
\text { u opuestas. (Opcional) }\end{array}$} \\
\hline \multicolumn{3}{|c|}{ Relaciones } \\
\hline Relación (0-9) & \multicolumn{2}{|c|}{$\begin{array}{l}\text { La fotografía catalogada podrá ser relacionada } \\
\text { con otras } 10 \text { fotografías si fuera necesario, } \\
\text { estableciendo relaciones de colección, } \\
\text { publicación, edición, etc. }\end{array}$} \\
\hline
\end{tabular}

Tabla II. Modelo de descripción exhaustiva del documento fotográfico
El programa informático para la gestión y catalogación de archivos fotográficos Photon, consta de un total de 20 tablas en base de datos que permiten gestionar las autoridades personales, familias, entidades, editoriales, categorías temáticas, colecciones, detalles, cámaras fotográficas, lugares y localizaciones topográficas de la fotografía. La tabla principal, se ha basado íntegramente en el modelo expuesto en la Tabla II, con un total de 124 campos, de los que 92 se destinan íntegramente a funciones descriptivoanalíticas de la forma, contenido y puntos de acceso de la fotografía. El diseño propuesto tiene múltiples particularidades para que su funcionamiento sea único. El área de localización fotográfica, está diseñado para registrar el edificio, planta, sala, estantería, balda y carpeta en la que se almacena la fotografía, mediante un módulo de edición de localizaciones topográficas. El proceso de identificación se adapta a todas las casuísticas por permitir la descripción de todos los posibles contextos de la fotografía, definir las propiedades de caracterización atendiendo a plano, encuadre, estructura formal, especialidad fotográfica, formato y soporte original. Las normas ISAD-G también fueron tenidas en consideración, introduciendo aquellos campos no utilizados por las demás, propios de las formas de ingreso y adquisición, la valoración, las condiciones de acceso y uso, la documentación asociada y notas. Por otro lado, el campo detalles, está diseñado para interactuar con el módulo de creación y edición de detalles fotográficos que amplifica las capacidades descriptivas del sistema, como se explicará más adelante. Los campos de clasificación temática, están diseñados para registrar las categorías de un módulo de edición de tesauros, totalmente integrado en la herramienta. Finalmente los campos de relaciones, permiten enlazar semántica y jerárquicamente las fotografías de la colección registrando su identificador, intitulación y tipo de relación. Esta última característica permitirá en futuros desarrollos implementar una web semántica RDF a partir de los fondos del archivo fotográfico que sea descrito con Photon.

\section{Diseño del programa Photon}

El programa Photon cuenta con distintos pliegos de especificaciones de diseño. La principal es lograr integrar el máximo nivel de descripción de la fotografía, aunando las principales normas y recomendaciones para su análisis y la disposición de módulos para el tratamiento y descripción de todas las autoridades. En relación a especificaciones de representación, navegación, vistas e informes, dispone de capacidad para imprimir hojas de contactos y catálogos fotográ- 
ficos en formato HTML, según se conforma la edición de las fotografías. En cuanto a las propiedades de administración del sistema, el programa cuenta con capacidad multi-usuario, que le permite soportar la catalogación y edición de múltiples documentalistas al mismo tiempo. Con respecto a las especificaciones singulares del programa destacan el modelo de interfaz que integra todas las áreas y campos de descripción junto con un visor para la fotografía objeto de análisis, su módulo de edición de autoridades y tesauro (Figura 1). El objetivo de este diseño es conseguir tener todas las herramientas de trabajo accesibles en una sola pantalla sin perder la perspectiva gráfica de la imagen que se está analizando.

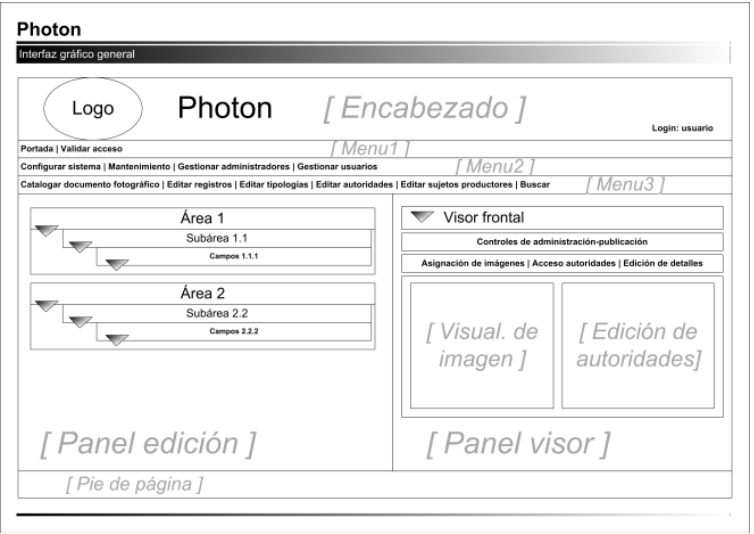

Figura 1. Esquema del interfaz del programa

A menudo en Documentación se utiliza el concepto documento secundario para mencionar al registro bibliográfico producto de la catalogación, en este caso el registro catalográfico de la fotografía. Pero existe un nuevo concepto de documento secundario en la fotografía al que denominaremos "La fotografía dentro de la fotografía" o más comúnmente, los detalles de la misma. Si bien distinguir los detalles en la descripción fotográfica es una tarea común, no lo es tanto generar terceras imágenes a partir de la primera, creando con ello segundas fotografías con una entidad propia, siendo en sí mismas un punto de acceso principal, gráfico y extrapolado del todo. Photon es capaz de generar tales detalles y tratarlos como un documento secundario derivado, que mejora las capacidades de recuperación sustancialmente. Para hacer efectiva esta capacidad, se ha diseñado una pantalla independiente que muestra la fotografía en sus dimensiones originales, así como un recuadro de recorte que puede moverse libremente a través de la superficie de la imagen, hasta encuadrar el detalle que se pretende describir. Para efectuar el recorte, el programa calcula las coordenadas desde el punto de origen de la fotografía, en la esquina superior izquierda de la pantalla (Figura 2).

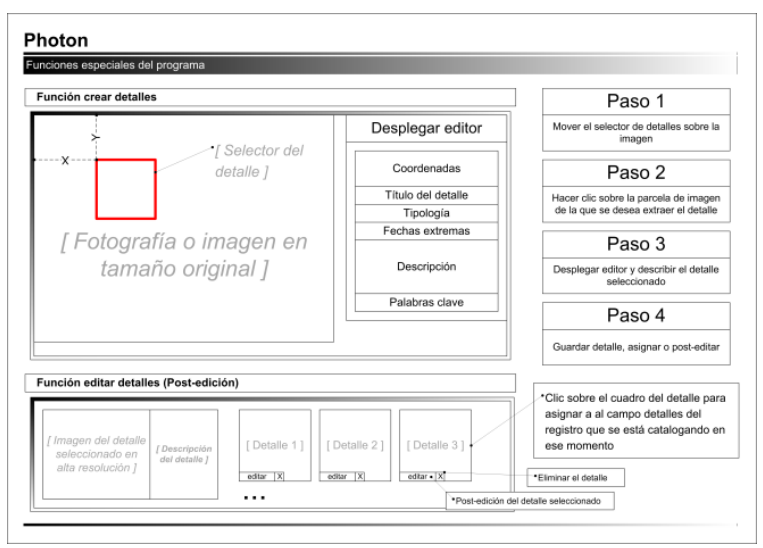

Figura 2. Esquema del módulo de detalles

En relación al establecimiento de tipologías para la caracterización de la fotografía, se ha primado la flexibilidad y total libertad de modificación de las propiedades del sistema (Figura 3).

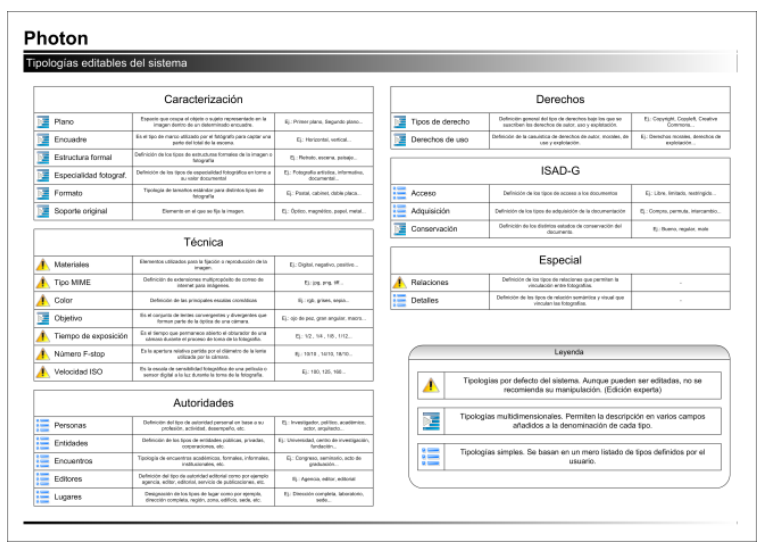

Figura 3. Tipologías del sistema

Esto es la posibilidad de editar los tipos de plano de la fotografía, encuadre, estructura formal, especialidad fotográfica, formato, soporte original, materiales, tipo MIME, color, objetivo, tiempos de exposición, número f-stop, velocidad ISO, tipos de autoridades personales, corporativas, editoriales, encuentros, lugares, tipos de derechos de la fotografía, tipología de accesos, adquisiciones, estados de conservación, tipología de relaciones entre las fotografías y tipología de detalles.

\section{Pruebas y futuras mejoras}

El programa Photon ha sido sometido a diversas pruebas de uso para comprobar sus límites de funcionamiento. Originalmente, está diseñado 
para trabajar con fotografías en formato JPG y PNG con un tamaño límite de imágenes en alta resolución que se sitúa en torno a los 14MB. Por otra parte, el programa ha sido diseñado para funcionar en red, mediante servidor AMP (Apache MySQL Php), quedando disponible para su experimentación en la siguiente dirección:

\section{http://www.mblazquez.es/testbench/photon/}

Dadas las capacidades del programa, se ha testado como herramienta docente en la asignatura de Documentación fotográfica durante el curso 2010-2011 en la Facultad de Ciencias de la Documentación de la Universidad Complutense (Blázquez Ochando, M., 2010b). El programa Photon también fue utilizado como herramienta catalográfica para la descripción de la colección fotográfica de Ripollés, presente en el Archivo y Biblioteca Regional de la Comunidad de Madrid (Rodríguez Rey, 2011).

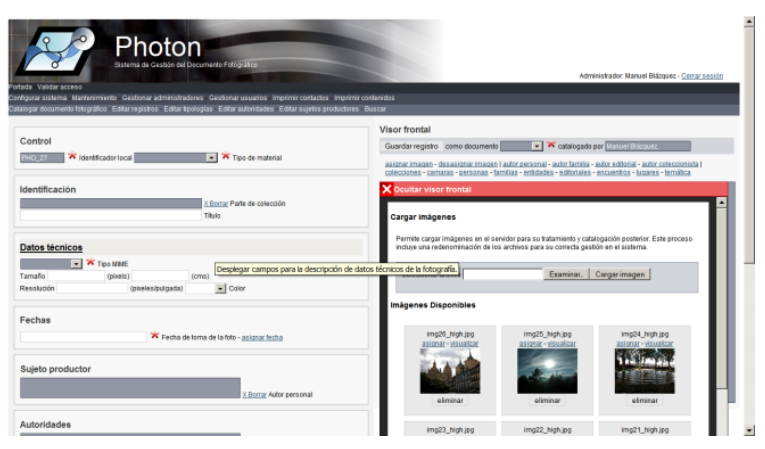

Figura 4. Vista real del programa Photon

Como resultado de su prueba de uso, se destacan varios aspectos mejorables. En primer lugar, la enorme extensión del esquema de descripción, que aún siendo flexible y correcto, debe ser más adaptable a las necesidades del catalogador. Dicho de otra forma, se debe permitir al documentalista elegir qué campos y áreas de descripción, de entre todas las disponibles, desea utilizar para su uso habitual. Ello se podrá subsanar durante el proceso de instalación de la herramienta, en la que se pedirá al usuario que componga su propio modelo de descripción personalizado, de acuerdo al esquema normalizado y original de Photon. Por otra parte, se destaca la utilidad del sistema de edición de detalles de la fotografía, pudiendo recuperar fotografías a partir de las descripciones de los mismos. Finalmente aunque el área de relaciones funciona correctamente en el programa, aún queda por finalizar el módulo que permite generar la web semántica de fotografías, trabajo clave para una recuperación de información más inteligente y productiva, de cara a la reutilización de los productos gráficos.

\section{Conclusiones}

Hasta el momento no existía un programa para la catalogación fotográfica que contemplara todas las demandas de la Documentación expresadas profusamente a lo largo de los últimos años. Ello se ha debido en gran medida a la caracterización y usos variados de la fotografía, lo que ha obligado a que las aplicaciones informáticas se especializaran en resolver casos concretos como la fotografía compartida en red, el registro bibliográfico de la fotografía o su registro archivístico, pero en ningún caso el registro completo de todas sus particularidades y características.

Aunque el programa Photon aún se encuentra en fase experimental, se logran compatibilizar los métodos de descripción ISBD, MARC21 e ISAD-G para el tratamiento documental de las fotografías, permitiendo el análisis más exhaustivo posible sobre una fotografía, habilitándolo para su uso y explotación en red.

Por primera vez en un programa de estas características, se emplea la técnica de recorte de detalles para su descripción y vinculación con la fotografía original, ampliando la riqueza del análisis documental, permitiendo tratar tales detalles como documentos con entidad propia y como puntos de acceso secundarios de cara a su reutilización.

\section{Referencias}

Argerich, I. (1997). Identificación técnica de las imágenes fotográficas monocromas. // Manual para el uso de archivos fotográficos: fuentes para la investigación y pauras de conservación de fondos fotográficos. Santander: Aula de fotografía, Universidad de Cantabria. 71-113.

Blázquez Ochando, M. (2010). Práctica de Documentación fotográfica automatizada. // Documentación Fotográfica. (2012-1-4)

Casanova Huerta, A. (2010). Software Libre una opción viable de la organización bibliográfica de fotografías: caso Biblioteca de las Artes. // XVI Reunión de Bibliotecarios de la Península de Yucatán. Mérida. 10-11.

Chica Blanco, G.; Osuna Arias, M.; Poves Pérez, E. (2009). La UTAD: una aportación en la gestión de servicios polivalentes. // SEDIC (Ed.). XI Jornadas de Gestión de la Información: Servicios polivalentes, confluencia entre profesionales de archivo, biblioteca y documentación. Madrid. 25-38.

Crisafulli Rodrigues, R. (2011). Análise e tematização da imagem fotográfica: determinação, delimitação e direcionamento dos discursos da imagem fotográfica. Brasília: Universidade de Brasilília.

Digital Curation Centre. (2012). Safeguarding European Photographic Images for Access (SEPIA). http://www.dcc.ac.uk/resources/external/safeguardingeuropean-photographic-images-access-sepia (2012-0404). 
Fox, L. (2003). La gestión de fondos fotográficos en entidades no comerciales. // Hipertext.net. 1. http://www.hiper text.net/web/pag246.htm\#5.2.

Gómez Díaz, R.; Gómez Isla, J.; Cordón García, J.; Domínguez López, J. (2007). El patrimonio fotográfico de la Universidad de Salamanca: la creación de una fototeca digital. // Ibersid. (2007) 177-194).

Hillmann, D. (2005). Using Dublin Core. http://dublincore.org/ documents/2005/11/07/usageguide/ (2011-06-01)

Ibáñez González, R.; López Monjón, J.; Sánchez Luque, M.; Villalón Herrera, R. (2009). El archivo fotográfico en la Unidad de Tratamiento Archivístico y Documentación (UTAD) del Centro de Ciencias Humanas y Sociales del CSIC. // SEDIC (ed.). XI Jornadas de Gestión de la Información: Servicios polivalentes, confluencia entre profesionales de archivo, biblioteca y documentación. Madrid. 225-236.

ICA. (2004). International Standard Archival Authority Record for Corporate Bodies, Persons, and Families. París: International Council on Archives.

ICA. (2007). International Standard for Describing Functions. Dresden: International Council on Archives.

ICA. (2000). ISAD(G): General International Standard Archival Description. Ottawa: International Council on Archives.

IFLA. (2008). Descripción Bibliográfica Internacional Normalizada ISBD. http://www.bne.es/es/Servicios/Normas Estandares/Docs/ISBDconsolidada.pdf (2011-06-12).
IPTC. (2011). IPTC Standards: NewsML G2 \& EventsML G2 Specification Version 2.9 Core Conformance Level. http://iptc.org/std/NewsML-G2/NewsML-G2_2.9.zip (2011-06-01).

Prints \& Photographs Online Catalog: Library of Congress. (2010). http://www.loc.gov/pictures/ (2010-7-10).

Rodríguez Rey, N. (2011). Las colecciones fotográficas del Archivo y Biblioteca Regional de la Comunidad de Madrid. // II Jornada Fotodoc: Las instituciones y sus fondos. Madrid.

Sánchez Vigil, J. (2002). Automatización de los archivos fotográficos: Modelos de fin de siglo: Oronoz y Scala. // BIBLIOS (13).

Sánchez Vigil, J. (2006). El documento fotográfico: historia, usos y aplicaciones. Gijón: Trea.

Sánchez Vigil, J. (1999). El Universo de la fotografía: prensa, edición, documentación. Madrid: Espasa.

Technical Standardization Committe on AV; IT Storage System and Equipment. (2002). // JEITA CP-3451: Exchangeable image file format for digital still cameras: Exif Version 2.2. http://www.exif.org/Exif2-2.PDF (201106-11).

Valle Gastaminza, F. (1999). El Análisis Documental de la Fotografía. // Manual de Documentación Fotográfica. Madrid: Síntesis. 113-131.

Enviado: 2012-04-14. Reenviado: 2012-07-10. Aceptado: 2012-08-21. (Inicialmente a la revista Ibersid) 